NBER WORKING PAPER SERIES

\title{
HYSTERESIS IN UNEMPLOYMENT: OLD AND NEW EVIDENCE
}

\author{
Laurence M. Ball \\ Working Paper 14818 \\ http://www.nber.org/papers/w14818 \\ NATIONAL BUREAU OF ECONOMIC RESEARCH \\ 1050 Massachusetts Avenue \\ Cambridge, MA 02138 \\ March 2009
}

This paper was prepared for "A Phillips Curve Retrospective" sponsored by the Federal Reserve Bank of Boston in June 2008. I am grateful for research assistance from Sandeep Mazumder and for comments from V.V. Chari, Jordi Gali, Engelbert Stockhammer, two anonymous referees, and conference participants. The views expressed herein are those of the author(s) and do not necessarily reflect the views of the National Bureau of Economic Research.

NBER working papers are circulated for discussion and comment purposes. They have not been peerreviewed or been subject to the review by the NBER Board of Directors that accompanies official NBER publications.

(C) 2009 by Laurence M. Ball. All rights reserved. Short sections of text, not to exceed two paragraphs, may be quoted without explicit permission provided that full credit, including $\odot$ notice, is given to the source. 
Hysteresis in Unemployment: Old and New Evidence

Laurence M. Ball

NBER Working Paper No. 14818

March 2009

JEL No. E24

\section{$\underline{\text { ABSTRACT }}$}

This paper argues that hysteresis helps explain the long-run behavior of unemployment. The natural rate of unemployment is influenced by the path of actual unemployment, and hence by shifts in aggregate demand. I review past evidence for hysteresis effects and present new evidence for 20 developed countries. A central finding is that large increases in the natural rate are associated with disinflations, and large decreases with run-ups in inflation. These facts are consistent with hysteresis theories and inconsistent with theories in which the natural rate is independent of aggregate demand.

Laurence M. Ball

Department of Economics

Johns Hopkins University

Baltimore, MD 21218

and NBER

lball@jhu.edu 


\section{INTRODUCTION}

Much of mainstream macroeconomics is based on an "accelerationist" Phillips curve. It was described by Friedman (1968) in his Presidential Address. A simple form is

$$
\pi=\pi_{-1}+\alpha\left(U-U^{*}\right), \quad \alpha<0
$$

Inflation depends on lagged inflation, often interpreted as a proxy for expected inflation. It also depends on the deviation of unemployment from the natural rate or NAIRU, $U^{*} .^{1}$

According to Friedman, shifts in aggregate demand coming from either monetary policy or other sources have short run impacts on unemployment. In the long run, however, $U$ always returns to $\mathrm{U}^{*}$. And $\mathrm{U}^{*}$ is not influenced by aggregate demand. Instead, it is determined by the supply side of the economy, especially frictions in labor markets. This means the classical dichotomy holds in the long run: monetary policy cannot cause long-run changes in unemployment.

Practically speaking, most economists think monetary policy can push $U$ away from $U^{*}$ for a few years. Paul Volcker, for example, managed to raise unemployment over 1980-83. However,

1 This is an old-fashioned backward-looking Phillips curve, replaced in much modern research by the forward-looking New Keynesian Phillips Curve. This paper is based on the premise that the old Phillips curve is a useful framework. The relative merits of old and new Phillips curves can be debated elsewhere. 
changes in unemployment over a decade or more are determined by changes in the natural rate. The fact that unemployment was substantially higher in France in 2000 than in 1980 has little or nothing to do with monetary policy.

This essay questions this conventional wisdom. I accept equation (1), but not the view that only supply-side factors influence $\mathrm{U}^{*}$. I believe in the concept of hysteresis advocated by Blanchard and Summers (1986): the natural rate can be influenced by the path of actual unemployment. If $U$ rises above $U^{*}$, for example, there exist mechanisms that pull $U^{*}$ upward. Since aggregate demand influences $U$, hysteresis means that demand also influences $U^{*}$.

Hysteresis is central to long-run unemployment movements in many countries. If we want to know why unemployment rose in much of Europe in the 1980s, or why it fell in the U.K. in the 1990s, or why it has remained relatively stable in the United States, we need to understand hysteresis.

This essay addresses two broad issues. The first is whether there is clear evidence of hysteresis effects. To put it differently, can we reject the hypothesis that the NAIRU, and hence the long run behavior of unemployment, is independent of aggregate demand?

The answer to this question is YES! I review past evidence on hysteresis and present some new evidence. 
The second broad issue is the nature of hysteresis. Through what mechanisms do short-run unemployment movements influence the NAIRU? What determines the strength of these effects in different countries and time periods? What are the implications for monetary policy?

My discussion of these topics is speculative. In my view, it's clear that some form of hysteresis exists, but it's not clear why. The relationships among unemployment, the natural rate, and inflation appear to be non-linear, but it's hard to pin down the non-linearities precisely. As a result, policy implications are not crisp.

In sum, hysteresis is an important phenomenon, but one that is not well understood. This means more research is needed. The topic of hysteresis has been neglected in recent years, and that should change.

II. THE PHILLIPS CURVE AND THE CHANGING NAIRU

Friedman (1968) says, "There is always a temporary tradeoff between unemployment and inflation; there is no permanent tradeoff. The temporary tradeoff comes not from inflation per se, but from unanticipated inflation, which generally means, from a rising rate of inflation." Eventually, says Friedman, unemployment returns to the natural rate.

Friedman's theory is summarized by equation (1). Today 
economists use "NAIRU" (for non-accelerating inflation rate of unemployment) as a synonym for the natural rate, because the natural rate is the unemployment level consistent with stable inflation. Forty years after Friedman wrote, equation (1) is a foundation for much of applied macroeconomics.

Friedman says the natural rate depends on features of the labor market such as minimum wages, labor unions, and frictions in matching the unemployed with job vacancies. He says that monetary policy cannot affect the natural rate.

Friedman suggests that the natural rate may change over time, and experience has shown that it does. In the United States, the NAIRU has varied by moderate amounts; according to estimates detailed below, it fell from $7.1 \%$ in 1980 to $4.9 \%$ in 2007. In Europe, the NAIRU has changed by larger amounts; in Spain, it rose from $6.5 \%$ in 1980 to 14.4 in 1995, then fell to $7.5 \%$ in 2007 .

A large literature has tried to explain changes in the NAIRU. Some researchers focus on changes in labor-market imperfections of the type discussed by Friedman (e.g. Nickell, 2005). Others examine interactions between such "institutions" and economic "shocks," such as the productivity slowdown and globalization (e.g. Blanchard and Wolfers, 2000; Blanchard, 2005). While the stories vary, they almost always involve the supply side of the economy. They presume that aggregate demand 
doesn't affect the NAIRU.

Much work focuses on Europe, where the NAIRU rose dramatically between 1960 and 2000. Mankiw (2006) tells undergraduates that there is a "leading theory" of this experience, one from the class of shock/institution theories. In this story, proposed by Krugman (1994) and others, the shock is a decrease in the demand for low-skill labor caused by technological change. The institutions are labor-market distortions that create wage rigidity. The equilibrium wages of low-skill workers have fallen but their actual wages have not, so unemployment has risen.

This story gets much of its appeal from the fact that it fits two data points, the United States and aggregate Europe. The U.S. has more flexible labor markets than Europe and has not experienced a rise in the NAIRU. We'll see, however, that the story works less well when we extend the sample from two economies to twenty.

Departing from most of the literature, this paper will argue that NAIRU changes are caused largely by shifts in aggregate demand. Demand influences actual unemployment, $U$, which in turn influences the natural rate through hysteresis channels. 
What are these channels? When Blanchard and Summers (1986) introduced the idea of hysteresis, they emphasized the "insideroutsider" theory of wage bargaining. When workers become unemployed, the remaining employed workers increase their wage targets, preventing the unemployed from getting their jobs back. In my view, however, there is little evidence for this kind of hysteresis effect.

There is more evidence for stories in which the long-term unemployed become detached from the labor market. These workers are unattractive to employers, or they don't try hard to find jobs. These stories fit evidence that hysteresis effects are stronger in countries with long-lived unemployment benefits. However, as discussed below, we have at best a hazy understanding of hysteresis mechanisms.

Allowing for hysteresis can greatly change our explanations for unemployment movements and our prescriptions for monetary policy. However, I don't view hysteresis as a radical departure from mainstream economic theory. It is not a rejection of Friedman's model, but a generalization of it. We expand the set of factors that cause the $U^{*}$ term in equation (1) to change over time: these factors include movements in actual unemployment as well as supply-side variables.

To study movements in the NAIRU, we need to estimate this variable. One simple method is to smooth the series for actual 
unemployment with the Hodrick-Prescott filter, based on the idea that the NAIRU is the long-term trend in unemployment. In this paper, I use a somewhat more sophisticated technique based on Ball and Mankiw (2002). This procedure modifies the results from a univariate smoother based on the behavior of inflation. During a period of falling inflation, for example, the Ball-Mankiw method produces lower NAIRU estimates than a univariate smoother, because falling inflation suggests that $U^{*}$ is below $U$.

The Appendix to this paper details my procedure for estimating the NAIRU. As an example of the results, Figure 1 shows the estimated NAIRU for France from 1980 to 2007 and compares it to a univariate unemployment trend (based on the HP filter with $\lambda=100)$. The estimated NAIRU is below the univariate trend over 1980-1997, reflecting the fact that inflation was falling. After that the two series converge, as inflation was stable.

I estimate NAIRU series for twenty countries: all the countries with populations above one million that were members of the OECD in 1985. This group includes 15 countries in western Europe, two each in North America and the Antipodes, and Japan.

I focus on the period since 1980. The NAIRU rose in many countries during the 1970s, but it is harder to detect hysteresis effects in that period. The large supply shocks make it harder to estimate Phillips curves and NAIRUs. Also, there was a major 
change in the real economy -- the productivity slowdown -- that probably increased the NAIRU in many countries. Hysteresis effects may have been secondary in the 1970s. Since 1980, however, hysteresis is a big part of the unemployment story.

\section{PREVIOUS EVIDENCE OF HYSTERESIS}

This paper will confess to major gaps in our understanding of hysteresis, but argue that it clearly exists in some form. That is, there is strong evidence against the hypothesis that movements in the NAIRU are independent of aggregate demand.

Here I discuss evidence for hysteresis in previous work. I emphasize two papers from some time ago: Ball (1997) and Ball (1999). The reason I focus on my own past work is not narcissism (or, at least, that's not the only reason). Beyond my work, there isn't much literature to review, as most researchers of the $21^{\text {st }}$ century have ignored hysteresis. However, the Boston Fed's invitation to write about the topic has rekindled my hope that economists will take it seriously. ${ }^{2}$ Disinflations in the $1980 \mathrm{~s}$

My 1997 paper examines changes in the NAIRU from 1980 to 1990. It uses estimates of the NAIRU produced by the OECD with a method that is similar in spirit to the Ball-Mankiw method.

2 Another promising sign is Stockhammer and Sturn (2008), which updates and extends the analysis in Ball (1999). 
According to these estimates, the NAIRU rose over the 1980s in 17 of the 20 countries in the sample. NAIRU changes ranged from $1.4 \%$ in the U.S. and Portugal to $+9.3 \%$ in Ireland.

I argue that NAIRU increases in the 1980s were caused largely by monetary tightenings aimed at reducing inflation. This conclusion is based on the following evidence:

- Measures of labor market distortions -- the degree of unionization, the severity of firing restrictions, and so on -are generally uncorrelated across countries with changes in the NAIRU. The only exception is a weak effect of the duration of unemployment benefits. Overall, this is evidence against the Krugman story about the interaction of labor demand shifts with labor market rigidities. That story predicts greater increases in the NAIRU where rigidities are greater.

- 19 of the 20 countries reduced inflation over the 1980s. There is a significant relationship across countries between the size of the inflation decrease and the change in the NAIRU. My interpretation is that larger disinflations required larger monetary tightenings, therefore raised unemployment more, therefore raised the NAIRU more through hysteresis.

- The change in the NAIRU is related not only to how much inflation fell, but also to the length of time over which disinflation occurred. Holding constant the total fall in inflation, a quick disinflation raises the NAIRU less than one 
that is drawn out over time. This result suggests mechanisms for hysteresis, as discussed below.

- While measures of labor-market distortions are generally uncorrelated with NAIRU changes, one of these variables -- the duration of unemployment benefits -- interacts significantly with the size and length of disinflation. That is, a given disinflation is associated with a larger rise in the NAIRU if unemployment benefits are available indefinitely. Once we control for this interaction, there is no direct effect of benefit duration. Again, this result is suggestive about hysteresis mechanisms. Policy Responses to Recessions

My 1999 paper examines the disinflations of the 1980s from another angle. Countries that reduced inflation generally experienced recessions and short-run rises in unemployment. However, the aftermath of disinflation varied: in some countries unemployment fell again after a few years, while in others the NAIRU rose and unemployment stayed high.

I argue that these differences are largely explained by the conduct of monetary policy. Some central banks tightened policy to reduce inflation, but reversed course when recessions occurred. They eased policy, pushing unemployment back down. other central banks tightened policy and kept it tight, so high unemployment persisted. 
To make this argument, the 1999 paper measures policy responses to recessions with changes in nominal and real interest rates (following Romer and Romer [1994]). The Fed is one central bank that cut rates sharply when recessions began, even though inflation had not yet fallen significantly. Many European central banks, by contrast, did not respond aggressively to recessions. They were reluctant to ease policy until inflation was clearly defeated. In addition, exchange rate concerns deterred some central banks from cutting interest rates.

The paper also measures the degree of hysteresis in each country by comparing increases in the NAIRU to short-run increases in unemployment during disinflation. I find that hysteresis effects are larger when central banks respond less strongly to recessions.

By itself, the fact that persistently tight policy causes persistently high unemployment is consistent with conventional macro, specifically the IS curve. Where the early-80s experience deviates from conventional models is in the behavior of inflation. If a monetary tightening doesn't affect the NAIRU, then equation (1) says inflation should fall as long as unemployment remains high. In many countries, inflation fell for a few years but then leveled off with unemployment still high. This meant by definition that the NAIRU rose. 


\section{Success Stories}

The NAIRU started falling in some countries in the mid1980s. Another part of my 1999 paper asks why. I focus on four countries that reduced the NAIRU (as estimated by the OECD) by at least 2 percentage points between 1985 and 1997. One is the U.K., which reversed the NAIRU run-up of the early 1980s; the others are Ireland, Netherlands, and Portugal.

Many observers attribute these NAIRU decreases to reductions in labor-market distortions (e.g. Siebert, 1997). But this interpretation does not withstand scrutiny. Countries where the NAIRU fell did implement some labor-market reforms, but they were modest. For example, the Netherlands slightly reduced the replacement ratio for UI, and the U.K. increased job counseling for UI recipients; neither put a time limit on benefits. Many other countries had similar or more extensive labor market reforms (Spain reduced the replacement ratio by the same amount as the Netherlands, and Belgium introduced a job-placement program similar to the UK's). The four countries where unemployment fell don't stand out as aggressive labor market reformers.

Instead, these countries stand out for their macroeconomic histories: they experienced demand expansions during the period when the NAIRU fell. The demand expansions reduced unemployment, which reduced the NAIRU through hysteresis. 
The U.K., for example, departed from the monetary policy of other European countries when it dropped out of the ERM in 1992 and lowered interest rates. Before that, in the late 1980s, the U.K. experienced the "Lawson boom," named after the Chancellor of the Exchequer who pursued fiscal expansion at the same time financial liberalization raised consumption and investment. The Bank of England was slow to tighten policy to choke off the boom, and inflation rose by more than five percentage points.

A substantial run-up in inflation also accompanied the NAIRU decreases in Portugal and the Netherlands (although not Ireland). As in the U.K., central banks did not raise inflation intentionally, but they failed to offset expansionary shocks. In my view, the coincidence of rising inflation with a falling NAIRU suggests that hysteresis is at work, that is, that a demand expansion is driving the NAIRU down. I return to this point below.

An important nuance is that the inflation run-ups in the U.K. and elsewhere were not permanent. A period of overheating and rising inflation was needed to reduce the NAIRU, but eventually inflation went back down. And when that happened, the NAIRU did not go back up.

IV. SOME NEW EVIDENCE

Here I present new evidence of hysteresis effects. I try to 
capture these effects in a simple way using data from 1980 through 2007.

My strategy is to focus on large changes in the NAIRU. I define large to mean a rise or fall of at least three percentage points. While my method for estimating the NAIRU is imprecise, an estimated change of $3 \%$ almost certainly indicates a substantial change in the true NAIRU.

I restrict attention to episodes in which the NAIRU changed by at least $3 \%$ within a period of ten years. This ten-year rule means I ignore changes in the NAIRU that are substantial but very gradual. It is harder to identify the sources of gradual changes than of relatively abrupt changes.

Usually the ten-year periods I identify lie within longer periods in which the NAIRU moves in the same direction. I define a NAIRU-change episode as the entire period in which the NAIRU moves in one direction. This implies that episodes start and end at peaks and troughs in the NAIRU series, or at the start and end of the 1980-2007 period.

In France, for example, the NAIRU increased from 1980, when it was $5.4 \%$, to 1996 , when it peaked at $9.4 \%$ (see Figure 1 ). This period qualifies for my set of episodes because the NAIRU rose by more than 3\% over the ten years from 1980 to 1990.

For the 20 countries in the sample, there are eight episodes of NAIRU increases that meet my criteria and nine episodes of 
NAIRU decreases. Table 1 lists the episodes, their dates, and the changes in the NAIRU over the episodes.

For each episode, I examine the behavior of inflation. This seems a natural way to distinguish between conventional stories about NAIRU changes and hysteresis theories. In hysteresis theories, changes in the NAIRU are driven by demand movements that initially push $U$ away from $U^{*}$. Assuming equation (1) holds, we should see rising inflation if strong demand is pushing the NAIRU down, and falling inflation if the NAIRU is rising. That is, inflation and the NAIRU should move in opposite directions.

The implications for inflation are different if real factors, such as changes in productivity growth or in labormarket distortions, cause changes in the NAIRU. In this case, one possibility is that the central bank adjusts $U$ to keep it near $U^{*}$. If that happens, inflation remains stable as $U^{*}$ changes.

Another possibility is that actual unemployment lags behind changes in the NAIRU. In this case inflation moves in the same direction as the NAIRU, the opposite of the comovement predicted by hysteresis theories. Orphanides (2000) argues that this happened in the United States in the 1970s. The NAIRU rose but policymakers did not recognize the change, so they tried to hold unemployment at the old NAIRU. With $U$ below $U^{*}$, inflation rose. In examining inflation behavior, as with unemployment, I 
look for large changes. I identify major disinflations, defined as a fall of at least $3 \%$ in "trend inflation." Following Ball (1994, 1999), trend inflation is measured by a nine-quarter centered moving average of inflation. Similarly, I identify major inflation run-ups, defined as increases in trend inflation of at least 3\%. I ask whether episodes of large changes in the NAIRU are associated with large disinflations or inflation runups. ${ }^{3}$

For each of the 17 episodes of major NAIRU changes, Table 2 shows the disinflations and inflation run-ups that occurred within the episode or overlapped with it significantly. The Table gives the dates and sizes of the inflation movements. A given NAIRU-change episode includes from zero to three inflationchange episodes.

3 An alternative would be to measure the total change in trend inflation over the NAIRU-change episode. One problem with this approach is that the results would be sensitive to the dating of starts and ends of episodes. These dates are hard to pin down with confidence, as they depend on how the series for unemployment is smoothed.

In addition, simply examining total inflation changes would hide the fact that significant fluctuations in inflation can occur within a NAIRU-change episode. As shown in Table 2, some episodes include both a disinflation and an inflation run-up. 
What do we learn from Table 2? Let's first examine the episodes of increasing NAIRUs. In six of these eight episodes, there was a significant disinflation, and no inflation run-up. The other two cases, Sweden and New Zealand, have the pattern of a disinflation followed by an inflation run-up followed by another disinflation. In both of these cases, each of the disinflations is larger than the intervening runup, and the total change in inflation over the three periods is highly negative (9.2\% in Sweden and $-14.7 \%$ in New Zealand). I interpret these two countries as having disinflationary regimes overall, despite an interruption in disinflation. ${ }^{4}$

I therefore count all eight episodes of NAIRU increases as involving disinflations. One way to put the result is that a major NAIRU increase is sufficient to tell us that a country experienced a major disinflation:

\section{NAIRU Increase --> Disinflation}

where the arrow does not indicate causality, but rather sufficiency in the sense that if you find an episode with a NAIRU increase, it is always an episode with a major disinflation. To put the same result a different way, a major disinflation is a

4 In New Zealand's case, the seesaw pattern of inflation may reflect wage and price controls, which were introduced in 1982 
necessary condition for a NAIRU increase.

Note that the reverse result does not hold: a disinflation is not sufficient for a NAIRU increase (equivalently, a NAIRU increase is not necessary for disinflation). Many countries in the sample experienced major disinflations without the NAIRU rising by $3 \%$. In some countries, such as the United States and Norway, disinflation occurred with almost no change in the NAIRU. Now let's examine decreases in the NAIRU. Here the story is more complex.

and lifted in 1984. 
of the nine NAIRU-decrease episodes, five include at least one inflation run-up. One of these five episodes, in the Netherlands, includes two run-ups and no disinflations. The other four include a disinflation as well as a run-up. However, in contrast to the cases of Sweden and New Zealand, the inflation run-ups and disinflations are similar sizes. In Australia, Ireland, and the U.K., the inflation run-up and disinflation (which are always contiguous) sum to $0.7 \%, 0.7 \%$, and $-1.5 \%$, respectively. Portugal is a special case of volatile inflation: there are two inflation run-ups with a large disinflation inbetween. The total inflation change over these episodes is $4.7 \% .^{5}$

Overall, I interpret these five episodes as consistent with hysteresis theories. In each case, the fall in the NAIRU produced a major inflation run-up at some point, suggesting demand expansions. These demand expansions reduced the NAIRU because they were not overwhelmed by much larger disinflations, as in Sweden and New Zealand.

The evidence shows, however, that reducing the NAIRU does not require a permanent increase in inflation. This is most

${ }^{5}$ A referee suggests that Australia's inflation run-up was caused by the introduction of a sales tax. However, the tax was introduced in July 2000, and most of the run-up occurred before then. My measure of trend inflation rose from $0.6 \%$ in 199801 to $4.2 \%$ in 2000Q2. Over the same period, a backward-looking fourquarter average of inflation rose from $-0.2 \%$ to $3.2 \%$. 
clear in Ireland and the U.K., where an inflation run-up was followed by a disinflation of similar magnitude. A successful theory of hysteresis will need to explain this pattern.

Four countries have decreases in the NAIRU with neither inflation run-ups nor disinflations: Finland, Italy, New Zealand, and Spain. Notice that, in all four cases, the episodes of falling NAIRUs followed large NAIRU increases, and only partly reversed these increases. The decreases look like some kind of mean reversion. One interpretation is that hysteresis effects are long-lived but not permanent. Tight monetary policy causes a rise in unemployment that lasts a long time, but eventually unemployment starts falling even if inflation is stable.

Note that four of the NAIRU decreases in Table 1 were not preceded by large NAIRU increases. These four episodes are among the five in which a NAIRU decrease was accompanied by a run-up in inflation. So the data suggest that a rise in inflation is necessary for reducing the NAIRU if mean reversion is not at work. We can summarize the results with

NAIRU Decrease --> Previous NAIRU Increase or Inflation Run-up

capturing the fact that all NAIRU decreases involve at least one of the factors on the right of the arrow.

We can also look at the inflation run-up / NAIRU 
relationship from the other direction. Table 3 lists all episodes of inflation run-ups since 1980 -- those included in Table 2 and those not included in Table 2 because they did not coincide with major changes in the NAIRU. The episodes are ranked by the size of the inflation increase.

I want to argue that inflation run-ups are associated with decreases in the NAIRU. That's not true for all of the run-ups in Table 3, but I have good excuses for discounting some of these cases. The two with asterisks are the Swedish and New Zealand episodes in which inflation run-ups interrupt regimes that are disinflationary overall. In the two cases with double asterisks, in Japan and Switzerland, a 3\% decrease in the NAIRU was impossible because the NAIRU was less than $3 \%$ when inflation started to rise.

That leaves nine inflation run-ups, and seven of them occurred during periods of NAIRU decreases. The two that didn't are the two smallest inflation run-ups on the list -- early runups in Australia and Finland. So, among inflation run-ups that were not sandwiched between big disinflations, and where the NAIRU was not below 3\% initially, the seven largest run-ups occurred during episodes of NAIRU decreases. To a first approximation we can say

Inflation run-up --> Decrease in NAIRU 
With some qualifications, an inflation run-up is sufficient for a NAIRU decrease (or a NAIRU decrease is necessary for an inflation run-up) .

To summarize, the patterns we see in these data are complex. It appears, however, that there are relationships of some type among large rises and falls in the NAIRU and large rises and falls in inflation. These relationships generally go in the direction predicted by hysteresis theories. The data are inconsistent with purely real theories of NAIRU changes, which predict either no relationship between NAIRU changes and inflation or a positive relationship.

V. OPEN QUESTIONS

While there is evidence that hysteresis exists, there are many open questions about the nature of the phenomenon. What Mechanism?

Why might hystersis exist? In introducing the concept, Blanchard and Summers explained it with an insider-outsider model of wage bargaining. These models have not been popular in recent years, however, and there may be good reason. There isn't much empirical evidence for insider-outsider models. In particular, they suggest that the degree of hysteresis should depend on wagesetting institutions, and that doesn't seem to be the case. For example, my 1997 paper finds no link between hysteresis and a 
country's level of unionization.

A more promising idea, which Blanchard and Summers discuss but deemphasize, involves the behavior of the long-term unemployed. The key idea is that these workers become detached from the labor market, both because they appear unattractive to employers and because they don't search vigorously for jobs. Consequently, while a high level of short-term unemployment puts downward pressure on wage inflation, a high level of long-term unemployment does not.

If this effect is strong, then it potentially explains hysteresis. One story is that a decrease in aggregate demand initially causes a rise in short-term unemployment, but this turns into long-term unemployment if the slump continues. The initial short-term unemployment causes inflation to fall, but then inflation stabilizes. At that point the NAIRU is higher because of the large pool of long-term unemployed.

This story is lent plausibility by evidence (in both my 1997 and 1999 papers) that a long duration of unemployment benefits magnifies hysteresis. Presumably it is more likely that the long-term unemployed become detached from the labor market if they can live on the dole indefinitely.

The story is also consistent with Llaudes (2007), who estimates Phillips curves with separate terms for long-term and short-term unemployment. For many countries, Llaudes finds that 
long-term unemployment has smaller effects on inflation. This result is stronger in countries with long-lived unemployment benefits.

Yet current stories about hysteresis mechanisms are speculative. More research is needed. In particular, researchers should directly examine the idea that the long-term unemployed become detached from the labor market. One method would be interviews of the type in Bewley (1999). Researchers could ask employers about their attitudes toward the long-term unemployed, and ask the unemployed about their search behavior. Non-linearities and State-dependence

In explaining the idea of hysteresis to students, I sometimes combine the Phillips curve, equation (1), with

$$
U^{*}=(1-\mu) U_{-1}^{*}+\mu U_{-1}
$$

Here, the NAIRU is pulled toward actual unemployment. The parameter $\mu$ measures the degree of hysteresis.

Empirically, however, it's clear that no such linear relationship exists. Changes in $U$ sometimes cause changes in $U^{*}$ and sometimes don't. It seems to depend on the past history of $U^{*}$ and the length of time that $U$ is pushed away from $U^{*}$. Hysteresis also appears asymmetric (e.g. an inflation run-up means it's very likely $U^{*}$ is falling, while disinflations often occur without $U^{*}$ rising).

As usual, it's difficult to measure non-linearities 
precisely. And our hazy understanding of hysteresis mechanisms means theory doesn't give us much guidance. However, there are promising avenues for research.

In particular, there should be more work examining the timeseries behavior of short-term and long-term unemployment. Suppose, as suggested by Llaudes' work, that long-term unemployment puts less pressure on inflation than short-term unemployment. Then we can learn about the varying effects of $U$ on $U^{*}$ by examining the evolution of $U$ of different durations. For example, we can directly check whether NAIRU increases are tied to shifts from short-term to long-term unemployment. We also might better understand why some countries reduce the NAIRU without significant effects on inflation, while inflation rises in other cases. Perhaps in some countries a demand expansion cuts into long-term unemployment without much effect on short-term unemployment. Elsewhere, a NAIRU decrease involves falling short-term unemployment, either because there is less long-term unemployment initially or because demand expands more rapidly. In this case, the effects on inflation are likely to be larger.

Policy Implications

If hysteresis exists, a broad lesson is that it's dangerous for central banks to focus policy too heavily on inflation, either through explicit inflation targeting or otherwise. If the 
natural rate is independent of monetary policy, then focusing on inflation can at worst exacerbate short-run unemployment movements. With hysteresis, by contrast, a given inflation target is consistent with more than one level of unemployment, even in the long run. A central bank might achieve its inflation target but create needlessly high unemployment in the process. A closely related point is that policy should ease when a recession occurs. This principle might seem like common sense, and the Fed has followed it (Romer and Romer, 1994), but not all central banks have. Ball (1999) finds that inadequate responses to recessions have contributed to hysteresis in some countries. One can dream up more novel ideas for policy based on the types of hysteresis effects that seem to exist. For example, maybe central banks facing high unemployment should expand demand, accepting a rise in inflation to reduce the NAIRU. Then they should tighten policy to reduce inflation, but reverse the tightening quickly, before a temporary rise in unemployment can push the NAIRU back up.

However, central banks generally presume that steady policies are better than tricky plans for first overheating and then underheating the economy. We would need much greater confidence in our understanding of hysteresis to give contrary advice. 
VI. CONCLUSION

In the last decade, mainstream economists have not paid much attention to the idea of hysteresis. Likely reasons include the theoretical appeal of long-run neutrality and our weak understanding of hysteresis mechanisms. In addition, many economists interpret the 1960 s and 70 s as showing that it's dangerous for central banks to target unemployment. Hysteresis stories evoke negative reactions because they seem like a step back toward the bad old days. ${ }^{6}$

Yet there is considerable evidence that hysteresis is an important factor in unemployment behavior. And there are clear avenues for research, for example using data on short-term and long-term unemployment. I hope hysteresis becomes a more popular topic in the future.

${ }^{6}$ Another factor is that Blanchard and Summers have been poor stewards of their hysteresis idea. Summers has been busy with other things. Blanchard has written extensively about unemployment since 1985, but much of his work explicitly or implicitly denies the existence of hysteresis. For example, Blanchard and wolfers (2000) take it as given that shifts in aggregate demand affect actual unemployment but not "equilibrium" unemployment. When even the creator of an idea doesn't seem to believe it, the idea loses credibility. 
APPENDIX: ESTIMATING THE NAIRU

To estimate the NAIRU, Ball and Mankiw (2002) first estimate the parameter $\alpha$ in

$$
\pi=\pi_{-1}+\alpha\left(U-U^{*}\right)+\varepsilon
$$

which is equation (1) with an error $\varepsilon$, which we interpret as a short-run supply shock. We estimate $\alpha$ by OLS, treating $U^{*}$ as a constant .

Rearranging equation (3) gives us

$$
U^{*}-(1 / \alpha) \varepsilon=U-(1 / \alpha)\left(\pi-\pi_{-1}\right)
$$

We construct the right side of this equation from the estimated $\alpha$ and data on unemployment and inflation, giving us the left side.

This expression, $U^{*}-(1 / \alpha) \varepsilon$, is the NAIRU minus a term proportional to the supply shock. We smooth this series with the Hodrick-Prescott filter to get NAIRU estimates.

The Ball-Mankiw procedure is internally inconsistent because it estimates a time-varying $U^{*}$, but assumes a constant $U^{*}$ to estimate $\alpha$. Here I resolve this inconsistency with an iterative procedure. Once I have a series for $U^{*}$, I use that series to reestimate equation (3), yielding a new estimate of $\alpha$. I use the new $\alpha$ to estimate a new series for $\mathrm{U}^{*}$, and so on until the results converge to an $\alpha$ and a $U^{*}$ series that are consistent. This procedure is applied to data from 1975 through 2007. (I only use NAIRU estimates for 1980-2007, but I start the 
estimation in 1975 to minimize endpoint problems.) I use a $\lambda$ parameter of 100 in the HP filter. 


\section{REFERENCES}

Ball, Laurence, "What Determines the Sacrifice Ratio," in Mankiw (ed.), Monetary Policy, 1994

Ball, Laurence, "Disinflation and the NAIRU," in Romer and Romer (ed.), Reducing Inflation: Motivation and Strategy, 1997

Ball, Laurence, "Aggregate Demand and Long-Run Unemployment," Brookings Papers, 1999

Ball, Laurence, and N. Gregory Mankiw, "The NAIRU in Theory and Practice," Journal of Economic Perspectives, 2002

Bewley, Truman, why Wages Don't Fall During a Recession, 1999

Blanchard, Oliver, "European Unemployment: The Evolution of Facts and Ideas," NBER Working Paper \#11750, 2005

Blanchard, Olivier, and Lawrence Summers, "Hysteresis and the European Unemployment Problem," NBER Macro Annual, 1986

Blanchard, Olivier, and Justin Wolfers, "The Roles of Shocks and Institutions in the Rise of European Unemployment: The Aggregate Evidence," Economic Journal, $200 \odot$

Friedman, Milton, "The Role of Monetary Policy," American Economic Review, 1968

Krugman, "Past and Prospective Causes of High Unemployment," in Kansas City Federal Reserve, Reducing Unemployment: Current Issues and Policy Options, $19 \overline{94}$

Llaudes, Ricardo, Johns Hopkins University dissertation, 2007

Mankiw, N. Gregory, Macroeconomics $6^{\text {th }}$ ed., 2006

Nickell, Stephen, "Unemployment in the OECD," Economic Journal, 2005

Orphanides, Athanasios, "The Search for Prosperity without Inflation," ECB Working Paper 15, 2000

Romer, Christina and David Romer, "What Ends Recessions?," NBER Macro Annual, 1994

Siebert, Horst, "Labor Market Rigidities: At the Root of Unemployment in Europe," Journal of Economic Perspectives, 


\section{7}

Stockhammer, Engelbert, and Simon Sturn, "The Impact of Monetary

Policy on Unemployment Hysteresis," IMK Working Paper 15/2008, October 2008. 
Table I

Large Changes in the NAIRU, 1980-1997

INCREASES

\begin{tabular}{lcc} 
Country & Period of Change & Size of Change \\
\hline Finland & $1980-1996$ & $9.7 \%$ \\
France & $1980-1996$ & $4.0 \%$ \\
Germany & $1980-2007$ & $5.6 \%$ \\
Ireland & $1980-1989$ & $5.2 \%$ \\
Italy & $1980-1996$ & $4.9 \%$ \\
New Zealand & $1980-1994$ & $4.9 \%$ \\
Spain & $1980-1995$ & $7.8 \%$ \\
Sweden & $1983-1999$ & $4.1 \%$
\end{tabular}

DECREASES

\begin{tabular}{lll} 
Country & Period of Change & Size of Change \\
\hline Australia & $1994-2007$ & $-4.0 \%$ \\
Finland & $1996-2007$ & $-4.3 \%$ \\
Ireland & $1989-2007$ & $-11.0 \%$ \\
Italy & $1996-2007$ & $-3.9 \%$ \\
Netherlands & $1988-2007$ & $-3.8 \%$ \\
New Zealand & $1994-2007$ & $-4.1 \%$ \\
Portugal & $1981-1992$ & $-3.3 \%$ \\
Spain & $1995-2007$ & $-6.9 \%$ \\
UK & $1987-2007$ & $-4.4 \%$
\end{tabular}


Table 2

Major Inflation Changes During Changes in the NAIRU

\begin{tabular}{|c|c|c|c|}
\hline NAIRU-Change Episode & & Major & Changes in Inflation \\
\hline Finland $80-86$ & $-8.2 \%$ & $81-86$ & \\
\hline France $80-96$ & $-10 \cdot 4 \%$ & $81-87$ & \\
\hline Germany $80-\odot 7$ & $-5.9 \%$ & $81-86$ & \\
\hline Ireland $80-89$ & $-16 \cdot 7 \%$ & $81-87$ & \\
\hline Italy 80-96 & $-14.4 \%$ & $80-87$ & \\
\hline NZ 80-94 & $-8.9 \%$, & $80-83$ & $+8.6 \%, 83-85 ;-14.4 \%, 85-92$ \\
\hline Spain 80-95 & $-5.2 \%$, & $89-97$ & \\
\hline Sweden 83-99 & $-8.2 \%$, & 80-86; & $+5.6 \%, 86-90 ;-6.6 \% 90-93$ \\
\hline
\end{tabular}

EPISODES OF NAIRU DECREASES

NAIRU-Change Episode Major Changes in Inflation

Australia, 94-07 -3.1\%, 95-98; +3.8\%, 98-01

Finland, $96-07$

Ireland, 89-07 +3.9\%, $98-01 ;-3.2 \%, 01-04$

Italy, 96-07

Netherlands, 88-07 +4.4\%, 86-89; +3.8\%, 97-๑९

$\mathrm{NZ}, \quad 94-07$

Portugal, $81-92 \quad+8.8 \%, 80-84 ;-17.5 \%, 84-87 ;+4.0 \%, 87-89$

Spain, $95-\odot 7$

UK， 87- $07 \quad+5.6 \%, 86-89 ;-7.1 \%, 89-93$ 
Table 3

All Inflation Run-ups, 1980-2007

\begin{tabular}{|c|c|}
\hline Portugal 80-84 & $8.8 \%$ \\
\hline New Zealand 83-85 & $8.6 \% *$ \\
\hline UK 86-89 & $5.6 \%$ \\
\hline Sweden 86-90 & $5.6 \% *$ \\
\hline Switzerland 86-90 & $4.7 \% * *$ \\
\hline Netherlands 86-89 & $4.4 \%$ \\
\hline Portugal 87-89 & $4.0 \%$ \\
\hline Ireland 98-01 & $3.9 \%$ \\
\hline Japan 87-90 & $3.9 \% * *$ \\
\hline Australia 98-01 & $3.8 \%$ \\
\hline Netherlands 97-๑๑ & $3.8 \%$ \\
\hline Australia 84-86 & $3.2 \%$ \\
\hline Finland 86-89 & $3.2 \%$ \\
\hline
\end{tabular}

* Preceded and followed by larger disinflations ** Initial NAIRU $<3 \%$ 
Figure 1

Unemployment in France

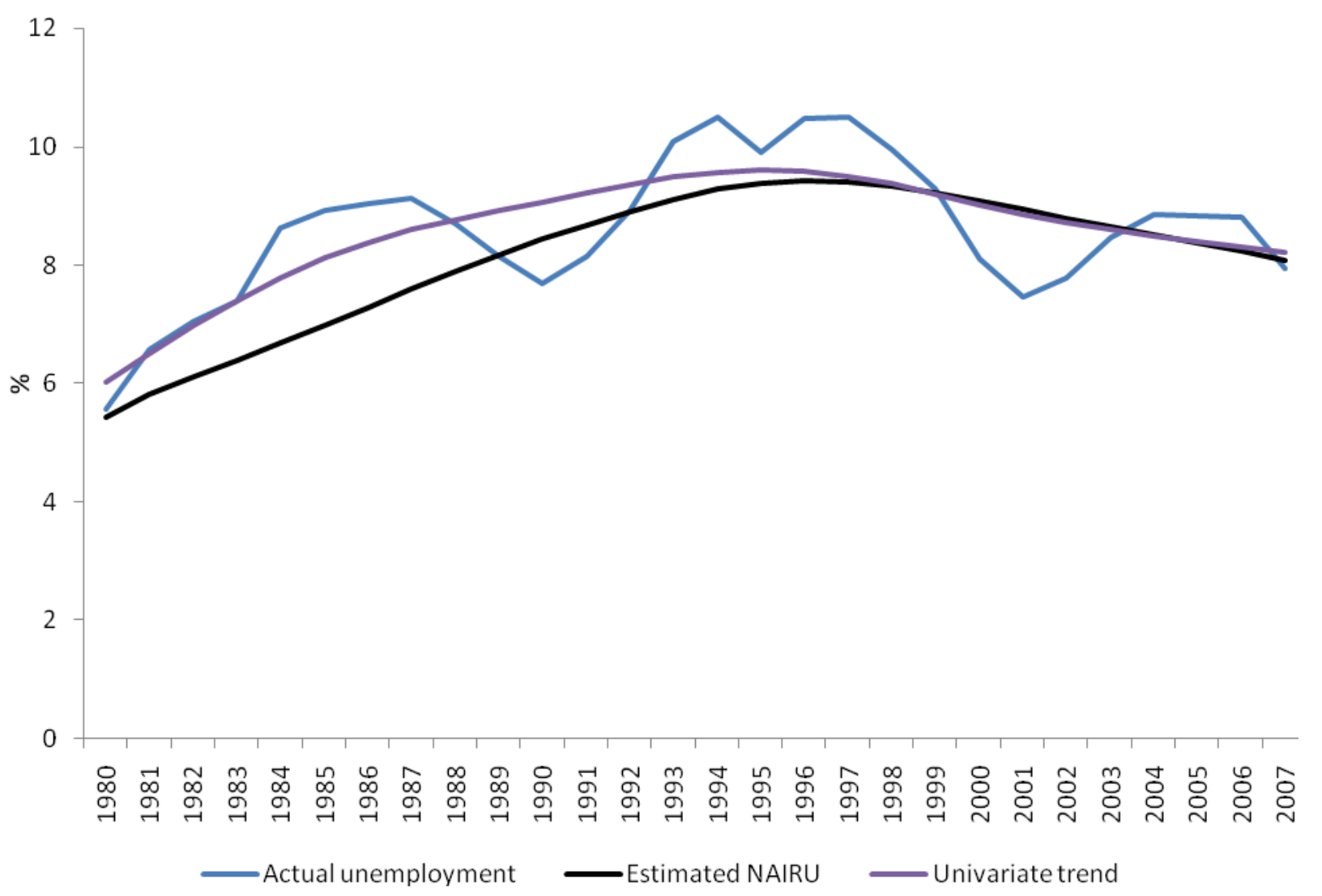

